\title{
The Forgotten Foods: Millet Based Food Products and Technological Advances in its Processing for Strengthening the Green Economy
}

\section{Niharika Sachdev*, Sangeeta Goomer}

Department of Food and Nutrition, Delhi University, Lady Irwin College, Mandi House, New Delhi - 110001

Key words: Nutrition, Food Security, Traditional food.

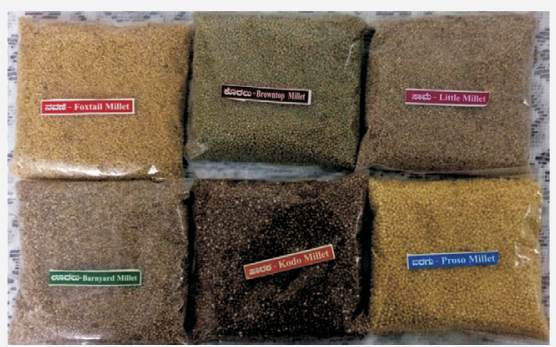

Samples of small millets commonly available in the Indian market

\section{Introduction:}

India is a diverse country in terms of people, their language, culture and traditions, foods production and consumption, land resources, biodiversity (plants and animal) etc. During the post green revolution, the tremendous rise in the production of wheat and rice has occurred, resulting in the acceptance of these cereals as the staple food. Unfortunately, the small nutritious grains such as millets and pseudocereals have lost their identity. Nutritional profile of millet makes it as extremely useful for human food. UNEP has defined green economy as "one that results in improvement of human well being and social equity, while significantly reducing environmental risk and ecological scarcities". Rajasekaran \& Gnanpandithan (2013) def ined green products as those:

- originallygrown,

- recyclable, reusable and biodegradable,

- natural ingredients,

- recycled contents, non-toxic chemical,

- contentswith approved chemical,

- do not harm or pollute the environment,

- will not be tested on animals,

- eco-friendly packaging i.e. reusable, refillable containers

\section{Landfill management:}

Millets are small sized monocotyledonous grains, rich in nutrients and are green foods of future. Large varieties of millets are grown in India viz., pearl millet (Pennisetum

\section{Abstract}

Millets are a small-seeded nutritious super crop of our ancestors which was forgotten while promoting green revolution in India. Technological advances in food and allied products processing have led to traditionally known nutritional and new therapeutic uses of millets. Millets crops are key to the problem of food security challenges of India. These 'green foods' offers great opportunity to tackle problems of nutrition security and unsustainable global production. Millets can act as a tool to reverse climate degradation, low productivity, and rising poverty. Transformation in the agricultural sector, innovation of newer technologies and the development of value chain is essential for millet utilization and thus the development of the green economy.

glaucum), finger millet (Eleusine coracana), kodo millet (Paspalum setaceum), proso millet (Penicum miliaceum), foxtail millet (Setaria italic), little millet (Panicum sumatrense), and barnyard millet (Echinochloa utilis) (Plate-1). Millets are usually processed to make it suitable for consumption and acceptable by consumers by altering its nutritional and sensory profile (Saleh et al., 2013). It undergoes several post-harvest operations before it reaches to consumer. These include dehulling/ debranning, milling, separation etc. Millets are also processed to produce commercially available products by puffing, baking, extruding, malting and fermenting. Some of the millet-based food products are infant foods, composite flour, ready to Eat products, bakery foods such as bread, biscuits, cakes, chocolate, cookies, Indian snacks such as papad, chakli, namkeens, puffed millet grains, porridge, pasta, noodles, health drinks, beer etc. The grains are either home cooked in the form of rice, porridge, roti or fermented snacks such as idli and dosai (Jaybhaye et al., 2014).

\section{Landfill management:}

Recently millets have been acknowledged as "Nutricereals" of India ( http://www.aicpmip.res.in/ pmnutricereals.pdf). Millets have better nutritional quality comparable to commonly consumed wheat and rice (Table1). They have a good amount of protein (except for limiting indispensable amino acid: lysine and threonine), carbohydrate especially insoluble dietary fiber, minerals including iron, calcium, phosphorus, magnesium, zinc and 
copper, B vitamins, antioxidants, polyphenols, and other bioactive compounds. Beside nutritional value, millet has potential health benefits in celiac disease cardiovascular, diabetes, cancer, aging and antimicrobial potential (Shahidi \& Chandrasekara, 2013). Millets have a low glycemic index. These are the great source of nutrition as well as food security as each of the millet is unique as compared to wheat and rice which are commonly consumed (Malathi et al.,2016). They can be consumed as functional food as well as a nutraceutical.

Table 1: Nutritional Value of Millet Grain in grams*

\begin{tabular}{llllll}
\hline Millet Grain & Protein & Fiber & Mineral & Iron & Calcium \\
\hline Pearl Millet & 10.6 & 1.3 & 2.3 & 16.9 & 38 \\
Finger millet & 7.3 & 3.6 & 2.7 & 3.9 & 344 \\
Foxtail Millet & 12.3 & 8 & 3.3 & 2.8 & 31 \\
Proso Millet & 12.5 & 2.2 & 1.9 & 0.8 & 14 \\
Kodo Millet & 8.3 & 9 & 2.6 & 0.6 & 27 \\
Little millet & 7.7 & 7.6 & 1.5 & 9.3 & 17 \\
Barnyard Millet & 11.2 & 10.1 & - & 15.2 & 11 \\
Rice & 6.8 & 0.2 & 0.6 & 0.7 & 10 \\
Wheat & 11.8 & 1.2 & 1.5 & 5.3 & 41 \\
\hline
\end{tabular}

( *Source:http://milletindia.org/wp-content/uploads/2015/o7/ II_National_Consulate.pdf)

\section{Cultivation of millet grains::}

Millet cultivation could play an important role in changing the situation of Indian farmers by generating income and meeting food demands, thereby reducing poverty level (Behera et al., 2017). Millets cultivation has potential agrarian advantages as these are easy to grow, adopt short rotation crops ( 65 days) etc. These crops withstand long environmental stresses. It requires fewer inputs, mostly organic. Also, quantitative loss by insect, pest, and diseases is low. The crops have higher storage life (> 2years). Besides, these advantages, millet cultivation contributes to the green economy. Their production leads to sustainable environment as they have low carbon footprints. Millet cultivation contributes to positive climate change by reducing the atmospheric $\mathrm{CO}_{2}$ (Bandhopadhya et al., 2017). They have the capacity to sequester carbon and this is how they adapt to climate change Also the need for synthetic fertilizer is quite low. Millet crops possess several traits which makes them climate adaptive by escaping environmental stresses (Table-2).

Table-2: Information on millet crop traits and benef its*

Crop Traits

Short life cycle; short stature; small leaf area; thickened cell wall; dense root system; $C_{4}$ photosynthesis; escape environmental stress; heat tolerance.

Benefits to Environment

Grow in dry lands; sequester $\mathrm{CO}_{2}$ thus reduce global warming

Benefits to Farmer

Easy to grow; provide food and nutritional security; crop diversif ication for livelihood security; generate employment and income; less inputs; less water requirement; improved growth and ecological enactment at warm temperatures makes it next generation crop

(*Bandhopadhya et al., 2017; Behera et al., 2017)

\section{Processing advancements of millet :}

Uses in Food Industry: millets are consumed as porridge, bread, steamed products like couscous, boiled rice like products, flaked and popped grains and various other health foods based on their gluten-free protein, low glycemic property, the presence of essential fatty acids, pigments and antioxidative property. But before that, millets undergo several foods processing operations to develop into commercial food products (Rai et al., 2008). Millets are dehulled or decorticated (removal of $10-12 \%$ of an outer surface of grain; germ) using rice mill or abrasive disk mill to improve nutritional and sensory quality. The process reduces antinutritional content and improves nutrients digestibility. Moistened millets grains are reduced to flour using hammer or roller mill. Another process that improves nutrients availability and digestibility is germination. In the germination process, grains are soaked and saturated in water and allowed to sprout in 2-3 days. Malting is germination of millets under control conditions. The process results in activation of aand $ß$-amylase and protease and improves protein quality, reduces polyphenol, phytic acid, oxalates, tannins and increases vitamins riboflavin, thiamin, ascorbic acid, and vitamin A but requires removal of rootlets and application of antimicrobial for longer shelf life. Millet grains are blanched by submerging grains in boiling hot water for about 30 sec and subsequently drying at $50^{\circ} \mathrm{C}$. Blanching of millet reduces enzyme activity, fat acidity, anti-nutrients. Dark colored millet grains on treatment with organic acids such as acetic acid tartaric acid or tamarind extract are decolorized. Other changes that occur in acid treatment are a reduction in anti-nutritional factors, reduces fat acidity, free fatty acids and lipase activity, and improved starch and protein digestibility. Similar improvements can be seen on combining acid treatment with high-temperature dry heat treatment of millet grains instead of dry heating at lower temperatures. Fermented millet products are traditionally consumed in India. Fermentation is different from germination in a way that microbial cultures are used to sour the product. Nutrient levels including B vitamins, iron, and their bioavailability improves significantly during fermentation. Protein and starch become more digestible. Enzymatic changes cause a reduction in phytic acid, tannin and polyphenol content. Parboiling of millet is traditionally done to obtain softly textured grains for making snack foods for diabetics, thick and dense gruels for infants, and a number of other rice-like products, example suji is obtained from parboiling of sorghum grains.

Uses in non-food industry: there are several other ways of utilizing millet. Active packaging systems are one of them. 
Foxtail millet starch along with clove oil has been used for development of active packaging material with antimicrobial and antioxidant activities for the packaging of Queso Blanco cheese to enhancing the shelf life (Yang et al., 2018). Pharmaceutical grade starch (PGS) can be produced from millets (Eze \& Alozie, 2015) for use as tablet excipient (Abdallah et al., 2014; Odeku, 2013). In a study, millet starch obtained from the grains of Pennistum glaucum, sorghum starch from the grains of Sorghum bicolor L. and cocoyam starch from the tubers of Colocasia esculenta was extracted and modified (freeze driedpregelatinized starch) to use as directly compressible excipients in tramadol tablet formulations for controlled release (Alabi et al., 2018). Also, millet starch can be used as a thickener in textile printing (Banerjee \& Sarkar, 2015).

Millet Starch is degraded by alpha-amylase enzyme easily. These amylases enzymes are extracted, purified for various biotechnological processes such as ethanol production, starch manufacture, food processing industries, textile industries, brewery industries (Agbo et al., 2017). Another major component of millet grain is gluten-free protein. Isolated millet proteins from grain are reported to have a therapeutic action against various diseases. For example, a novel $(35 \mathrm{kDa})$ protein extracted from foxtail millet bran (FMBP) has targeted anti-colon cancer effects and may serve as a therapeutic agent against colon cancer (Shan et al., 2014). Peptide sequence with antioxidant potential has been identified by hydrolysis of pearl millet protein using trypsin enzyme (Agrawal et al., 2016). Hypertension and alleviate associated cardiovascular diseases may ameliorate on ingestion of foxtail millet protein hydrolysates (both raw and extruded hydrolysates) (Chen et al., 2017). Millet derived protein such as proso millet protein is a potential encapsulating agent and used for the delivery of lipophilic compounds such as curcumin (Wang et al., 2018).

\section{Conclusion and future direction:}

In spite of advancement in food processing technique, several constraints to commercialization exist that hinders millet food industry growth such as social stigma associated with millet consumption in poor Indians, presence of coarse fiber and pigments in grain, lack of dissemination of information on newer technologies, government policies support, substitution of millets in food products which are acceptable for traits that are absent in millet, for example, millet substitution in baked products. Thus millets must be used smartly as natural resource sustainable production systems depending on their evidence-based potentiality.

\section{References:}

Abdallah, D.B., Charoo, N.A., \& Elgorashi, A.S. (2014): Comparative binding and disintegrating property of Echinochloa colona starch (difra starch) against maize, sorghum, and cassava starch. Pharm. Biol., 52(8):935-943.
Agbo, K.U., Eze, S.O., Okwuenu, P.C., Ezike, T.C., Ezugwu, A.L., \& Chilaka, F.C. (2017): Extraction, Purification and Characterization of Sprouting Pearl Millet Alpha-Amylase for Biotechnological Applications. L. Plant Biochem. Physiol., 5(174):1-6.

Agrawal, H., Joshi, R., \& Gupta, M. (2016): Isolation, purification and characterization of antioxidative peptide of pearl millet (Pennisetum glaucum) protein hydrolysate Food Chem., 204:365-372.

Alabi, C.O., Singh, I. \& Odeku, O.A. (2018): Evaluation of natural and pregelatinized forms of three tropical starches as excipients in tramadol tablet formulation. J. Pharma. Invest., 48(3):333-340.

Bandyopadhyay, T., Muthamilarasan, M. \& Prasad, M. (2017): Millets for next generation climate-smart agriculture. Front. Plant Sci., 8:1266.

Banerjee, A. \& Sarkar, A.K. (2015): Extraction, characterization, and evaluation of proso millet starch in textile printing. AATCCJ. Res., 2(6):14-19.

Behera, M.K. (2017): Assessment of the state of millets farming in India. MOJEcol. Environ. Sci., 2(1):16?20.

Chen, J., Duan, W., Ren, X., Wang, C., Pan, Z., Diao, X. \& Shen, Q. (2017): Effect of foxtail millet protein hydrolysates on lowering blood pressure in spontaneously hypertensive rats. Eur. J. Nutr., 56(6):2129-2138.

Eze, S.O.E. \& Alozie, K.N. (2015): Assessment of Pharmaceutical Grade Starch Produced From Some Local Grains-Corn, Sorghum and Millet.J. Chem. Soc. Niger., 40(1):118-122.

Jaybhaye, R.V., Pardeshi, I.L., Vengaiah, P.C. \& Srivastav, P.P. (2014): Processing and technology for millet based food products: a review. L. Ready Eat Food, 1(2):32-48.

Malathi, B., Appaji, C., Reddy, G. R., Dattatri, K. \& Sudhakar, N. (2016): Growth pattern of millets in India. Indian J. Agr. Res., $50(4): 382-386$.

Odeku, O.A. (2013): Potentials of tropical starches as pharmaceutical excipients: A review. Starch, 65(1-2):89-106.

Rai, K.N., Gowda, C.L.L., Reddy, B.V.S., \& Sehgal, S. (2008): Adaptation and potential uses of sorghum and pearl millet in alternative and health foods. Compr. Rev. Food Sci. Food Saf., $7(4): 320-396$

Rajasekaran, M.R. \& Gnanapandithan, N. (2013): A Study on Green Product and Innovation for Sustainable Development. Glo. J. Manag. Bus. Stud., 3(6):625-632.

Saleh, A.S., Zhang, Q., Chen, J., \& Shen, Q. (2013): Millet grains: nutritional quality, processing, and potential health benef its. Comp. Rev. Food Sci. Food Saf., 12(3):281-295.

Shahidi, F., \& Chandrasekara, A. (2013): Millet grain phenolics and their role in disease risk reduction and health promotion: $\mathrm{A}$ review. L. Func. Food., 5(2):570-581.

Shan, S., Li, Z., Newton, I. P., Zhao, C., Li, Z., \& Guo, M. (2014): A novel protein extracted from foxtail millet bran displays anticarcinogenic effects in human colon cancer cells. Toxicol. Lett., 227(2):129-38.

Yang, S. Y., Cao, L., Kim, H., Beak, S. E. \& Song, K. B. (2018): Utilization of Foxtail Millet Starch Film Incorporated with Clove Leaf Oil for the Packaging of Queso Blanco Cheese as a Model Food. Starch, 70(3-4):1700171.

Wang, L., Gulati, P., Santra, D., Rose, D. \& Zhang, Y. (2018): Nanoparticles prepared by proso millet protein as novel curcumin delivery system. Food Chem., 240, 1039-1046. 